\title{
Separation and recovery of vanadium from spent vanadium pentaoxide catalyst by Cyanex 272
}

Archana Saily Painuly

\begin{abstract}
Background: The contact process preferably used vanadium pentaoxide as catalyst to increase the rate of reaction of producing sulphuric acid. Sulfuric acid plants regularly require catalyst replacement in order to cope with process improvements. The spent catalyst is considered as hazardous solid waste and cannot be discarded untreated owing to presence of high amount of vanadium and other associated metals. Because of significant environment implications of spent catalyst wastes, it is imperative to recover valuable metals present in them. The recovery of precious materials or metals from waste will not only help in mitigating environment problem due to metal pollution but also help improve the economy of the country. The purpose of this research work is to develop method to recover vanadium from spent $\mathrm{V}_{2} \mathrm{O}_{5}$ catalyst.

Results: The detailed study of extraction, separation and recovery of vanadium from leached spent catalyst solution of composition; $\mathrm{V}, 3.6 \% ; \mathrm{Al}, 2.1 \%$; $\mathrm{Fe}, 1.3 \%$; Ti, $0.8 \%$ and less than $1 \%$ of $\mathrm{Cr}$ and $\mathrm{Pb}$ is reported in this paper. Cyanex 272 (bis $\left(2,4\right.$, 4-trimethylpentyl) phosphinic acid) has been explored for the recovery of vanadium from spent $\mathrm{V}_{2} \mathrm{O}_{5}$ catalyst. The effects of different parameters like, $\mathrm{pH}$, solvent concentration, organic to aqueous ratio etc. were optimised for the complete extraction and recovery of vanadium.

Conclusions: The proposed procedure gives high purity vanadium with almost a quantitative yield ( 99\%) and of course free from closely associated metals. The extractants could be reused up to ten cycles with no significant change in the extraction capability.
\end{abstract}

Keywords: Extraction; Organophosphines; Cyanex; Vanadium; $\mathrm{V}_{2} \mathrm{O}_{5}$ catalyst

\section{Background}

Vanadium is generally used for alloying steel and iron. Major uses of vanadium as oxide are in the production of oxidation catalysts for the manufacturing of sulphuric acid, in petroleum refinery for catalytic cracking of heavy oil and in many industrial processes. The vanadium has seen a steady rise in demand from the steel construction industry as building regulations increasingly call for improved strength and lighter construction materials. More recently the development of large-scale vanadium-redox flow batteries (VRFBs) for use in energy grid storage applications has opened up a new demand stream for vanadium (Gan and Dong 2010; Lazenby 2012).
The increased demand of vanadium by the industry has put extra pressure for the production of metal which has caused gradual depletion of natural resources containing $\mathrm{V}$. This has encouraged researchers to look for alternative or secondary sources such as industrial or electronic wastes, spent catalysts and other by products. Among secondary resources, the metal recovery from spent catalyst is gaining interest due to both, its hazardous nature and stringent regulations associated with disposal methods (Furimsky 1996; Srichandan et al. 2013). The life of a catalyst varies from 3 to 6 years depending upon the impurities in the feed and number of cycles used (Park et al. 2006). The deactivated catalyst can be reactivated by a number of different mechanisms, both chemical and physical in nature. After a number of deactivation-activation cycles, the catalyst is discarded as waste (Furimsky 1996). 
Due to heavy metal content, spent catalyst is categorized as hazardous waste (Rapaport 2000) and therefore need to be processed for the total metal recovery prior to its safe disposal. Recycling of spent catalyst is also important from environmental and economical perspective. One of the major benefits is a significant energy saving using recycled materials compared to virgin materials. It also helps in waste management by limiting the amount of waste on landfilled (Fornalczyk 2012).

Main techniques for the separation and purification of vanadium in spent catalyst leach solutions are precipitation, carbon adsorption, ion exchange and solvent extraction. Precipitation offers low cost and simple operation, however, high purities of vanadium cannot be achieved by this (Zeng et al. 2006; Zeng and Yong Cheng 2009b). The loading capacities of activated carbon for vanadium are relatively low, resulting in no industrial application. The scale of application of ion exchange in industry is limited owing to high cost of exchangers although it can be used to separate vanadium from other associated impurities almost completely thereby producing high purity products. Solvent extraction is the well established cost effective operation for purification of vanadium in their aqueous solutions (Fornalczyk 2012 Marafi and Stanislaus 2008). Solvent extraction technique is one of the most attractive alternatives for this purpose. It has certain inherent advantages such as ease of continuous operation, high throughputs and improved economics coupled with flexibility of handling a variety of metal solutions from diverse sources (Zeng and Cheng 2009a).

A significant effort has been made to recover vanadium from aqueous solutions by solvent extraction technique using various extractants. During the latter half of the twentieth century, reagents like -diketones, oxines, oximes, dithizones, dithiocarbamates, dithiols, high molecular weight amines (HWWA) and organophosphorus compounds came into prominence. Among these HMWA and organophosphorus compounds emerged out as popular commercial extractants for vanadium. However, the problem of emulsion formation in the former prevented quantitative phase separation (Gupta and Krishnamurthy 1992; Nguyen and Lee 2013; Saily 1997; Tavakoli and Dreisinger 2014).

As of now alkylphosphorus compounds are more or less dominating the market of extractants. Among organophosphorus, DEHPA (bis (2-ethylhexyl) phosphoric acid) and TOPO (Tri-n-octylphosphine oxide) have been extensively used for extraction behaviour of vanadium (Hughes and Biswas 1991; Islam and Biswas 1980; Juang and Lo 1993; Li et al. 2011; Sato et al. 1980). However, there are few problems with these solvents for example DEHPA readily form an emulsion or a third phase during stripping of Mo and V from the loaded solvent with the ammonia solution. Poor selectivity is another disadvantage of these extractants since they can co-extract several metals, including impurity elements such as iron and aluminium even at low pH (Sahu et al. 2013). TOPO shows high extraction coefficient but poor selectivity. It is known to extract approximately 30 metal ions from aqueous solutions (Shaeri et al. 2015).

Cyanex reagents are structurally different than most of the commercially available organophosphorous reagents (e.g. DEHPA, DDPA, TBP, EHPEHPA etc.), where alkyl groups are bonded directly to the phosphorus atoms through $\mathrm{P}-\mathrm{C}$ bonds rather than $\mathrm{P}-\mathrm{O}-\mathrm{C}$ bonding. The presence of hydrophobic P-C bonding in Cyanex reagents renders them to be less susceptible to hydrolysis and less soluble in water than other reagents (Chen and Wang 2010; Saily and Tandon 1998).

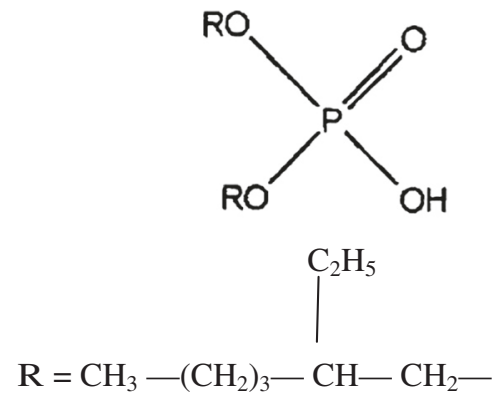

\section{DEPHA or Di(2-ethylhexyl)phosphoric acid}

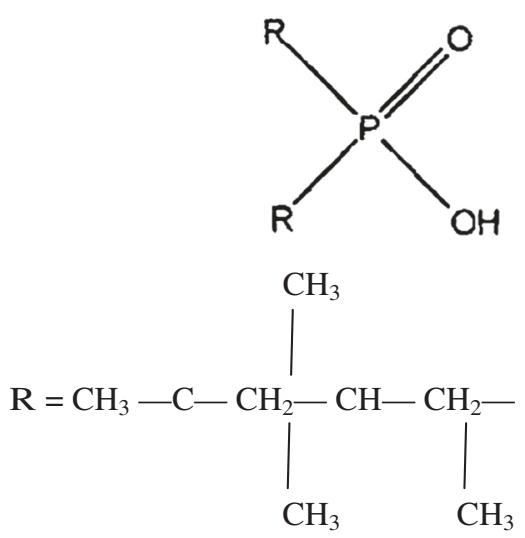

CYANEX 272 or Bis(2,4,4-trimethylpentyl)phosphinic acid

Extraction equilibria studies of vanadium using Cyanex 272 (bis (2, 4, 4-trimethylpentyl) phosphinic acid) have been reported by researchers (Li et al. 2012; Saily and Tandon 1998; Zang et al. 1996; Zeng and Cheng 2009a) and few studies have also been conducted on its recovery from wastes. Most of separation and recovery was done employing synergetic effects of two or more 
extractants (Noori et al. 2014; Shaeri et al. 2015; Tavakoli and Dreisinger 2014; Wu et al. 2012), however the occurrence of white turbidity and a third phase formation was the major problem observed during stripping of $\mathrm{V}$ from the loaded organic ( $\mathrm{Li}$ et al. 2011; Sahu et al. 2013). The present study focussed on the extraction studies of $\mathrm{V}$ along with closely associated metal ions from nitrate solutions and its quantitative recovery from spent $\mathrm{V}_{2} \mathrm{O}_{5}$ catalyst employing Cyanex 272 without synergetic effect, which certainly enhance financial viability of methodology. A complete separation scheme for the recovery of vanadium from spent $\mathrm{V}_{2} \mathrm{O}_{5}$ catalyst was developed and designed to extract impurities in the organic phase leaving behind vanadium in raffinate to overcome the problem of turbidity and third phase formation during stripping.

\section{Result and Discussion}

\section{Effect of solvent concentration on metal extraction}

The concentration of Cyanex 272 was varied from 5\% to $30 \%(\mathrm{v} / \mathrm{v})$, to optimize the concentration of the solvent for the extraction of metals from leached spent $\mathrm{V}_{2} \mathrm{O}_{5}$ catalyst solution. The $\mathrm{pH}$ of leach solution and $\mathrm{O} / \mathrm{A}$ ratio were maintained at a constant of 2 and 1 , respectively. The percentage extraction of metal ions first shows an increase with the increasing solvent concentration up to $25 \%$ and then becomes constant (Figure 1). Cyanex 272 shows a greater affinity for titanium over iron at a lower solvent concentration. For all other experiments $30 \%$ solvent was used.

\section{Effect of $\mathrm{pH}$ on the extraction}

Extraction efficiency of vanadium is highly dependent on $\mathrm{pH}$ because it forms different anionic complexes at low pH (Zeng and Yong Cheng 2009b). The extraction behaviour was studied at different $\mathrm{pH}$ ranging from 0 to 3. The other experimental conditions were fixed as O/A 1:1, Cyanex 272 concentration 30\% (v/v). The extraction behaviour of $\mathrm{V}$ along with $\mathrm{Al}, \mathrm{Fe}, \mathrm{Ti}, \mathrm{Cr}$ and $\mathrm{Pb}$ is shown in Figure 2. The extraction of $\mathrm{Fe}$ and $\mathrm{Al}$ increased with increasing $\mathrm{pH}$, however, $\mathrm{V}$ follows reverse pattern that is extraction efficiency increased with decreasing $\mathrm{pH}$. Extraction of $\mathrm{Ti}$ is constant (80\%) at lower $\mathrm{pH}$ and shows a quantitative increase at higher $\mathrm{pH}$ from 1 to 3 . Co-extraction of $\mathrm{Cr}$ and $\mathrm{Pb}$ is almost negligible $(<5 \%)$ and is not shown. At the equilibrium $\mathrm{pH}$ of 3 , the distribution ratios for $\mathrm{V}, \mathrm{Al}$, Fe and $\mathrm{Ti}$ were found to be $0.04,21,64$ and 37 respectively. The separation factor of $\mathrm{Ti} / \mathrm{V}, \mathrm{Al} / \mathrm{V}$ and $\mathrm{Fe} /$ $\mathrm{V}$ were determined to be 880,500 and 1523 , respectively, which is a good separation value. To separate $\mathrm{V}$ from $\mathrm{Fe} \mathrm{Al}$ and $\mathrm{Ti}$ from the leached solution the $\mathrm{pH}$ was fixed to 3 .

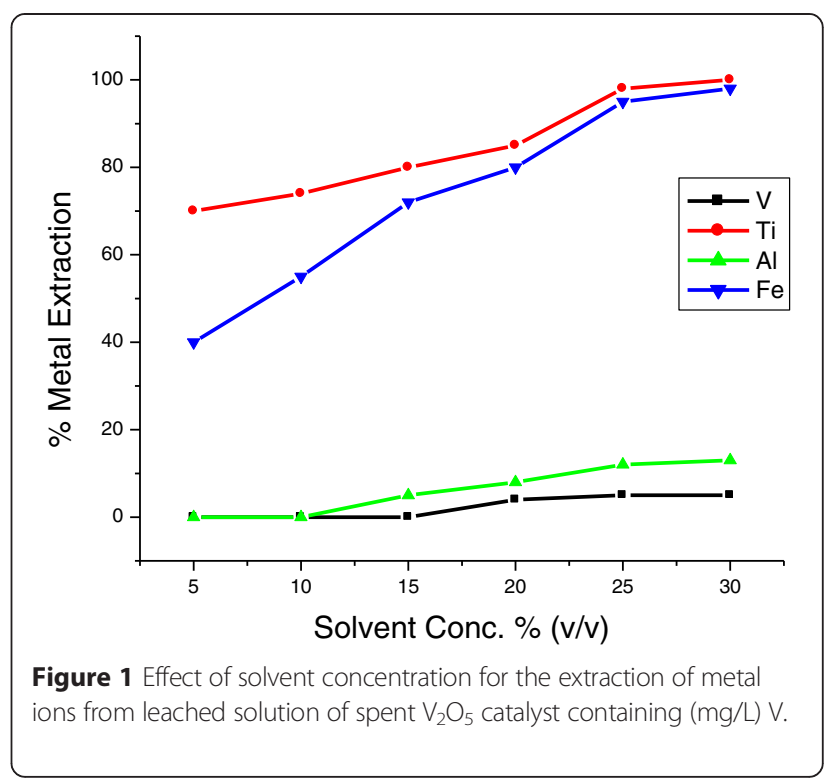

\section{Saturation loading capacity of Extractant}

At $\mathrm{pH} 3$ the 30\% (v/v) Cyanex 272 was contacted with the leach solution of composition $\mathrm{V}-366 \mathrm{mg} / \mathrm{L}, \mathrm{Al}-215 \mathrm{mg} / \mathrm{L}$, Fe-129 mg/L and Ti-75 mg/L, in a multiple contact mode. The O/A phase ratio was maintained at 1:1 to study the saturation loading capacity of the solvent. The metal uptake from the aqueous phase continued to increase after each contact, however, from third contact onwards, the extracted metal showed precipitation at the interface of aqueous and organic layer (Figure 3). The solvent was loaded with about $660 \mathrm{mg} / \mathrm{L}$ of $\mathrm{Al}, 453 \mathrm{mg} / \mathrm{L}$ of $\mathrm{Fe}$ and $256 \mathrm{mg} / \mathrm{L}$ of $\mathrm{Ti}$ after the fourth cycle, which was assumed as the saturated loading capacity of 30\% Cyanex 272 for $\mathrm{Al}, \mathrm{Fe}$ and Ti. At pH 3,

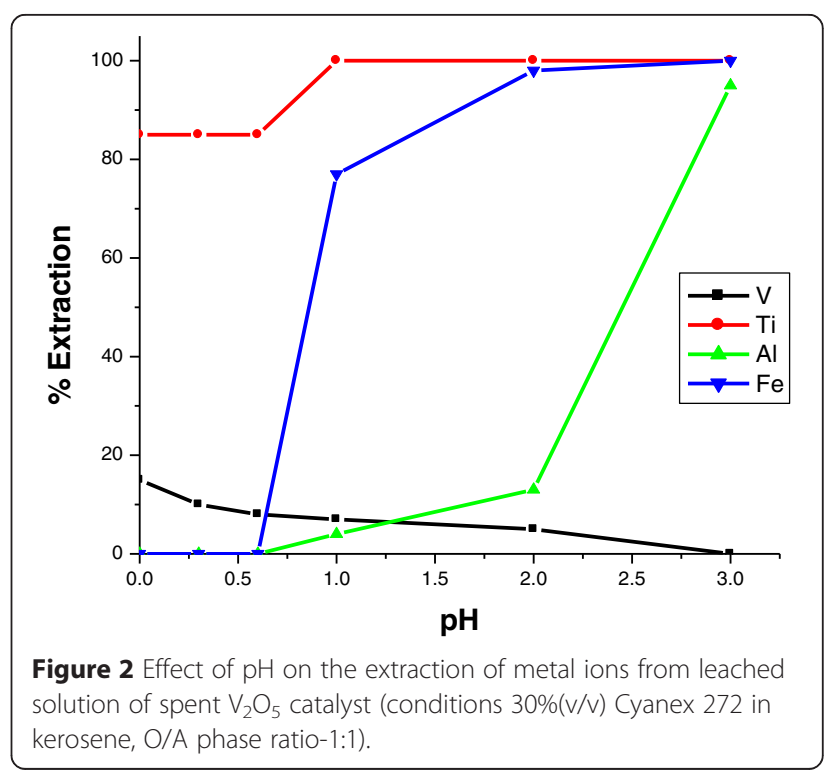




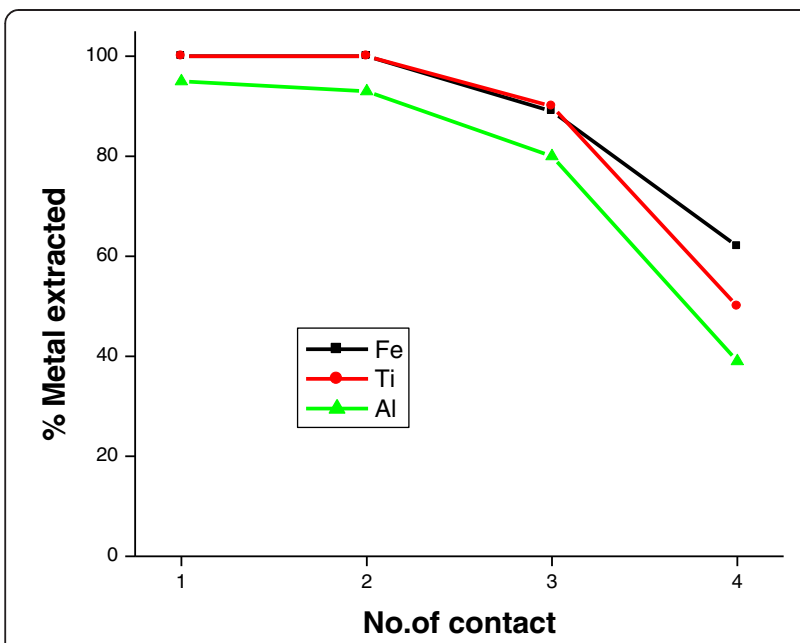

Figure 3 Saturation loading of Fe, Ti and Al by Cyanex 272 (30\%), Aqueous feed (mg/L) V- 366, Ti-75, Al-215 and Fe-129, pH- 3, O/A ratio $-1: 1$.

the vanadium uptake was found less than 5\% (Figure 2) in multiple contact modes and hence it is the most enabled condition for the separation of vanadium from $\mathrm{Al}, \mathrm{Fe}$ and $\mathrm{Ti}$.

\section{Effect of $\mathrm{O} / \mathrm{A}$ phase ratio}

The distribution of $\mathrm{V}, \mathrm{Al}, \mathrm{Fe}$ and Ti present in leached solution was carried out at a different $\mathrm{O} / \mathrm{A}$ ratio (organic to aqueous) using 30\% Cyanex 272 at $\mathrm{pH} 3$ to determine the condition for the maximum extraction and subsequent separation of these metals. The O/A phase ratio was varied from 1:5 to 5:1. The solution containing V- $366 \mathrm{mg} / \mathrm{L}, \mathrm{Al}-215 \mathrm{mg} / \mathrm{L}, \mathrm{Fe}-129 \mathrm{mg} / \mathrm{L}$ and Ti-75 mg/L with $\mathrm{pH} 3$ was used for the experiment. It was observed that with increase in $\mathrm{O} / \mathrm{A}$ phase ratio from 0.2 to 3.0, extraction of $\mathrm{Fe}, \mathrm{Ti}$ and $\mathrm{Al}$ also increased (Table 1). In order to determine the extraction isotherms, the McCabe -Thiele plot was constructed from phase ratio variation study for $\mathrm{Fe}$ and $\mathrm{Al}$. The McCabe -Thiele plot represented in Figures 4 and 5 for $\mathrm{Fe}$ and $\mathrm{Al}$, respectively, predicted requirement of 2 theoretical stages at $\mathrm{O} / \mathrm{A}$ ratio at 1:2 for complete extraction of associated metal ions ( $\mathrm{Al}, \mathrm{Fe}$, and $\mathrm{Ti}$ ) and subsequent separation of vanadium from leached solution of spent $\mathrm{V}_{2} \mathrm{O}_{5}$ catalyst.

Table 1 Percentage extraction of $\mathrm{Fe}, \mathrm{Ti}$ and $\mathrm{Al}$ at different organic/aqueous ratio study from leached solution of spent $\mathrm{V}_{\mathbf{2}} \mathrm{O}_{\mathbf{5}}$ catalyst

\begin{tabular}{llllllll}
\hline O/A Ratio \% Extraction & $\mathbf{0 . 2}$ & $\mathbf{0 . 2 5}$ & $\mathbf{0 . 3 3}$ & $\mathbf{0 . 5}$ & $\mathbf{1}$ & $\mathbf{2}$ & $\mathbf{3}$ \\
\hline $\mathrm{Fe}$ & 60 & 67 & 77 & 90 & 98 & 99 & 99 \\
$\mathrm{Ti}$ & 65 & 70 & 80 & 95 & 100 & 100 & 100 \\
$\mathrm{Al}$ & 40 & 60 & 70 & 85 & 90 & 95 & 95 \\
\hline
\end{tabular}

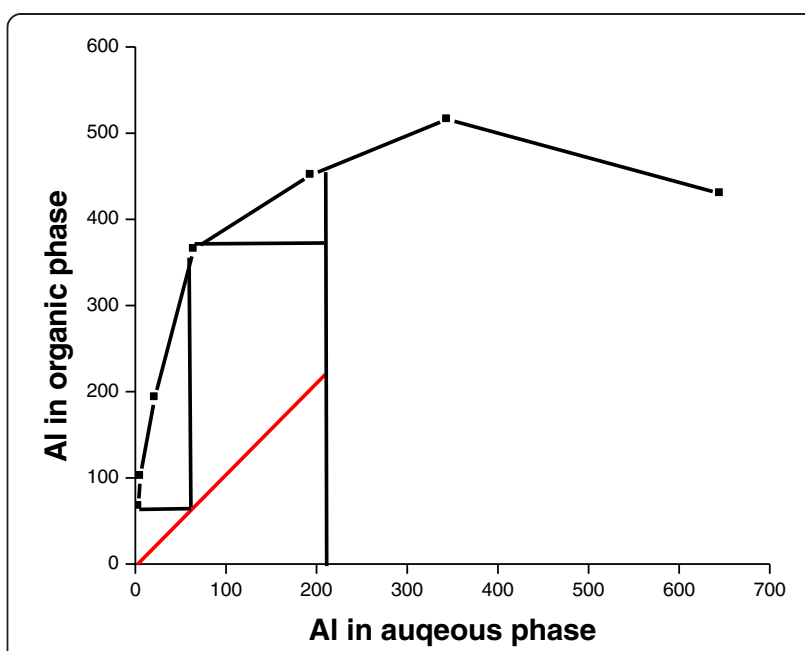

Figure 4 McCabe-Thiele diagram for determination of number of stages for complete extraction of aluminium from leached solution of spent $\mathrm{V}_{2} \mathrm{O}_{5}$ catalyst (conditions 30\%(v/v) Cyanex 272 in kerosene, $\mathrm{pH}-3$ ).

In order to validate the number of stages determined from the McCabe -Thiele plots (Figures 4 and 5), counter current simulation study for the complete extraction of Fe and $\mathrm{Al}$ from the leached solution was carried out. It was observed that $99 \%$ of $\mathrm{Fe}$ and $95 \%$ of $\mathrm{Al}$ could be extracted in two stages leaving behind vanadium in aqueous phase using 30\% Cyanex 272 with O:A ratio of 1:2 at an aqueous phase $\mathrm{pH}$ of 3 . The problem in stripping of vanadium from loaded Cyanex 272 encountered by other researchers due to turbidity and third phase formation could be overcome in this investigated process as vanadium remains in aqueous phase.

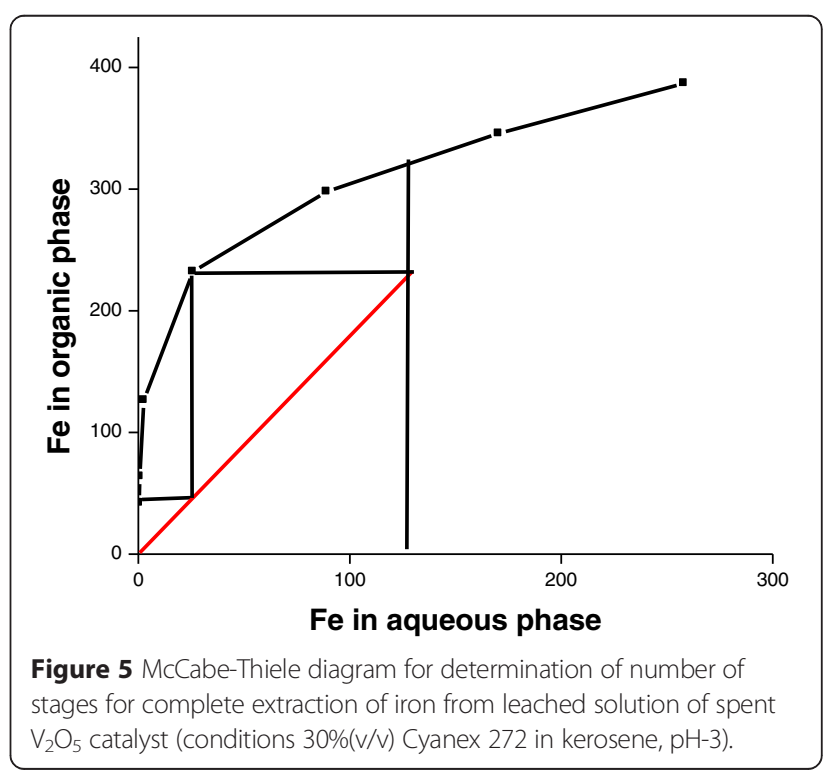




\section{Stripping of iron, titanium and aluminium from loaded Cyanex 272}

Leached solution of spent $\mathrm{V}_{2} \mathrm{O}_{5}$ catalyst containing $\mathrm{V}, \mathrm{Al}$, Fe and Ti loaded to the Cyanex 272 by two stage counter current process as determined by McCabe -Thiele plot (Figures 4 and 5) using O/A phase ratio of 1:2. The loaded organic containing Al; $730 \mathrm{mg} / \mathrm{L}, \mathrm{Fe} ; 262 \mathrm{mg} / \mathrm{L}$, and $\mathrm{Ti}$ $155 \mathrm{mg} / \mathrm{L}$ was washed first with $5 \%\left(\mathrm{NH}_{4}\right)_{2} \mathrm{CO}_{3}$ for selective stripping of $\mathrm{Ti}$ from Fe and $\mathrm{Al}$. After the removal of $\mathrm{Ti}$, Fe was stripped from organic phase by washing it first with10 $\mathrm{ml}$ of $3.0 \mathrm{M} \mathrm{HCl}$ and then with $10 \mathrm{ml}$ of $0.10 \mathrm{M}$ oxalic acid. Al left behind after $\mathrm{Ti}$ and Fe removal was stripped from organic phase by washing it with $10 \mathrm{ml}$ of $0.1 \mathrm{M}$ tartaric acid. The percentage recovery of $\mathrm{Al}, \mathrm{Fe}$ and Ti was 98, 99 and 99, respectively.

The organic phase, after removal of $\mathrm{Fe}, \mathrm{Ti}$ and $\mathrm{Al}$ can be regenerated by washing it twice with water. The regeneration capacity of this extraction system was tested by carrying out successive extraction stripping cycles of kerosene solution of Cyanex 272. The results show no significant change in the extractability of reagents upto ten cycles.

\section{Process flow sheet of vanadium recovery from spent $\mathrm{V}_{2} \mathrm{O}_{5}$ catalyst}

Based on above investigation, a process flow sheet was developed for the recovery of vanadium from leached solution of spent $\mathrm{V}_{2} \mathrm{O}_{5}$ catalyst (Figure 6). In this flow sheet, vanadium can be effectively separated from $\mathrm{Al}, \mathrm{Fe}$ and $\mathrm{Ti}$ in two stages counter current extraction process using 30\% Cyanex 272. Vanadium rich raffinate, which was almost free from $\mathrm{Al}, \mathrm{Fe}$ and $\mathrm{Ti}$ was precipitated with $\mathrm{NH}_{4} \mathrm{OH}$ at a $\mathrm{pH}$ about 8 . The precipitate was filtered and calcined at $500^{\circ} \mathrm{C}$ for $1 \mathrm{hr}$ to produce corresponding oxide in pure form.

\section{Conclusions}

The above investigations project the potential of Cyanex 272 for the recovery of vanadium from spent $\mathrm{V}_{2} \mathrm{O}_{5}$ catalyst of composition V- $366 \mathrm{mg} / \mathrm{L}, \mathrm{Al}-215 \mathrm{mg} / \mathrm{L}, \mathrm{Fe}-129 \mathrm{mg} / \mathrm{L}$ and $\mathrm{Ti}-75 \mathrm{mg} / \mathrm{L}$. In the proposed extraction process vanadium remains in aqueous phase which has two major advantages. First, it not only succeeded in dealing with the problem of turbidity but also eliminated the problem of third phase formation, which was encountered by past researchers during the stripping of vanadium from loaded Cyanex 272 and second the possibility of loss of vanadium is negligible. The formation of emulsion and crud is the severe disadvantage in solvent extraction operations as this constitutes a major solvent loss which affects the operating costs. Further, the extraction process using Cyanex 272 also recovered aluminium, iron and titanium besides vanadium, which are present in significant amount in spent $\mathrm{V}_{2} \mathrm{O}_{5}$ catalyst.

The extraction isotherm, constructed at $\mathrm{pH} 3$ with O:A phase ratio of 1:2 through McCabe-Thiele plot predicted two stage counter current process. Vanadium free from $\mathrm{Al}$, Fe and $\mathrm{Ti}$ was selectively recovered as their ammonium salt, which was calcined at $500^{\circ} \mathrm{C}$ to get the vanadium as oxide $\left(\mathrm{V}_{2} \mathrm{O}_{5}\right)$. Recovery of vanadium as $\mathrm{V}_{2} \mathrm{O}_{5}$ was found to be $99 \%$. The extractants could be reused simply by washing with water upto ten cycles with no significant change in the extraction capability.

The present bench level study successfully showed pure and quantitative recovery of vanadium as oxide. However,

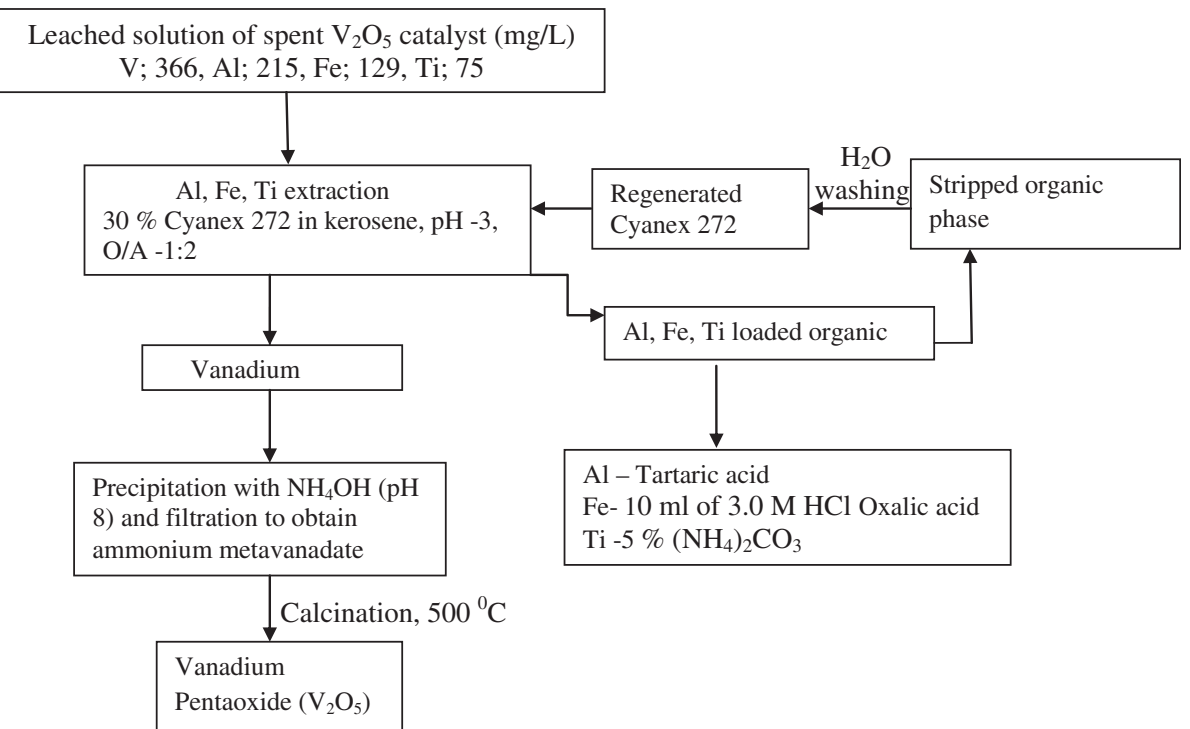

Figure 6 Flow sheet for the recovery of vanadium from leached solution of spent $\mathrm{V}_{2} \mathrm{O}_{5}$ catalyst using Cyanex 272. 
few additional experiments like leaching process time, phase contact time and effect of different stripping agents along with deep understanding of extraction mechanism need to be considered as future work before it can be scaled up from bench level to plant scale.

\section{Methods}

Cyanex 272 was obtained from Cytec, USA and was used without further purification. The sample of spent $\mathrm{V}_{2} \mathrm{O}_{5}$ catalyst was obtained from Projects and Development India Limited (PDIL), Sindri (India). All chemicals used were of analytical purity. Stock solutions of metal ions were standardized by usual complexometric titrations (Meites 1963; Schwarzenbach and Flaschka 1969).

$1 \mathrm{~g}$ of the powdered spent $\mathrm{V}_{2} \mathrm{O}_{5}$ catalyst $(\mathrm{V}, 3.5 \% ; \mathrm{Al}$, $2.0 \%$; $\mathrm{Fe}, 1.3 \%$,Ti, $0.8 \%$; and less than $1 \%$ of $\mathrm{Cr}$ and $\mathrm{Pb}$ ) was repeatedly (four times) digested with aqua-regia. The residue was treated with $10 \mathrm{ml}$ of concentrated $\mathrm{HNO}_{3}$ and filtered. The filtrate was boiled with nitric acid, cooled and made upto a final volume of $100 \mathrm{ml}$. The metal ion concentrations in the leach solution of catalyst agree fairly well with the composition data provided by the supplier. In order to get a representative value five separate samples of the catalyst were dissolved and processed by the proposed extraction procedure.

The solvent extraction and stripping experiments were carried out by shaking the required volumes of aqueous and organic phase in a glass -stopper separatory funnel at room temperature $\left(25 \pm 2{ }^{\circ} \mathrm{C}\right)$ for 3 minutes to ensure equilibration. After phase separation the metal concentration in aqueous and stripped organic phase were analysed by Inductive Coupled Plasma-Atomic Emission Spectroscopy (ICP-AES). The distribution ratio (D) and per cent extraction (\% E) of metal ions were calculated by the usual method.

$$
\begin{aligned}
& \mathrm{D}=\frac{[\mathrm{M}] \text { org }}{[\mathrm{M}] \mathrm{aq}} . \\
& \% \mathrm{E}=\frac{\left(\mathrm{D}\left(\frac{\text { Vorg }}{\text { Vaq }}\right)\right)}{1+\left(\mathrm{D}\left(\frac{\text { Vorg }}{\text { Vaq }}\right)\right)} \mathrm{X} 100 .
\end{aligned}
$$

where, $[\mathrm{M}]_{\text {org }}$ is the concentration of a metal in the organic phase and $[M]_{\mathrm{aq}}$ is concentration in the aqueous phase. $V_{\text {org }}$ and $V_{a q}$ are the volume of the organic and aqueous phases, respectively. The different results reported in the paper are the average of minimum of two determinations. Blank determinations were carried out wherever necessary and the corrections were made if required. During the analysis for different parameters blanks, duplicates, spikes and standards were processed on $5 \%$ basis. The percentage recovery for spiked samples in metal determinations ranged from $94 \%$ to $104 \%$, which indicate that the results are accurate and unbiased. Relative percent difference of duplicate measurements was less than $10 \%$, which is a satisfactory precision.

\section{Competing interests}

The author declares that there are no identified conflicts of interest associated with this publication and there has been no major financial support for this work that could have influenced its outcome.

\section{Authors' contributions}

ASP has designed the research plan and carried out the experiments. The analysis and data interpretation has done by author. The author has written and approved the final manuscript.

\section{Authors' information}

Dr. Archana Saily Painuly is a researcher in Shri Ramswaroop Memorial University, India. Dr. Painuly's research interest cover broad spectrum of hydrometallurgical and bio-hydrometallurgical methods with interest from basic mechanism to industrial applications.

\section{Acknowledgements}

The author is grateful to Cytec Industries, USA for providing the gift of Cyanex extractants. Assistance from the Projects and Development India Limited (PDIL), Sindri (India) is highly appreciated. The financial assistance from the Council of Scientific and Industrial Research (CSIR), New Delhi, India is gratefully acknowledged. Author would like to express thanks and appreciation to the Chancellor, Pro Chancellor and Vice Chancellor of Shri Ramswaroop Memorial University, India for their help and encouragement to carry out this research.

Received: 23 December 2014 Accepted: 2 April 2015

Published online: 15 April 2015

\section{References}

Chen L, Wang YZ (2010) Aryl polyphosphonates: useful halogen-free flame retardants for polymers. Materials 3:4746-4760

Fornalczyk A (2012) Industrial catalysts as a source of valuable metals. JAMME 55:864-869

Furimsky E (1996) Spent refinery catalysts: environment, safety and utilization. Catal Today 30:223-286

Gan Y, Dong H (2010) Review of Applications of Vanadium in Steels. Proceedings of International Seminar on Production and Application of High Strength Seismic Grade Rebar Containing Vanadium Beijing, China

Gupta CK, Krishnamurthy N (1992) Extractive metallurgy of vanadium (process metallurgy). Elsevier, Netherlands

Hughes MA, Biswas RK (1991) The kinetics of V(IV) extraction in the acidic sulphate DEHPA-n- hexane system using the rotating diffusion cell technique. Hydrometallurgy 26:281

Islam F, Biswas RK (1980) The solvent Extraction of V (IV) with HDEHP in benzene and kerosene. The solvent extraction of $V$ (IV) from sulphuric acid solutions with bis(2-ethylhexyl)phosphoric acid in benzene and kerosene. J Inorg Nucl Chem 42:415

Juang RS, Lo RH (1993) Stoichimetery of vanadium (IV) extraction from sulphate solutions with bis(2-ethylhexyl)phosphoric acid dissolved in kerosene. J Chem Eng Jpn 26:219

Lazenby H (2012) High-tech uses for vanadium to drive demand, prices higher. Minning weekly Creamer Media's, Johannesburg, South Africa

Li X, Wei C, Deng Z, Li M, Li C, Fan G (2011) Selective solvent extraction of vanadium over iron from a stone coal/black shale acid leach solution by D2EHPA/TBP. Hydrometallurgy 105:359-363

Li X, Wei C, Wu J, Li C, Li M, Deng Z (2012) Thermodynamics and mechanism of vanadium(IV) extraction from sulphate medium with D2EHPA, EHEHPA and CYANEX 272 in kerosene. Trans Nonferrous Metals Soc China 22:461-466

Marafi M, Stanislaus A (2008) Spent hydrprocessing catalyst management: A review Part II Advances in metal recovery and safe disposal methods. Resour Conserv Recycl 53:1-26

Meites L (1963) Hand book of analytical chemistry. Mc Graw-Hill, New York 
Nguyen HT, Lee MS (2013) Recovery of molybdenum and vanadium from acidic leaching solution of spent catalysts by solvent extraction. J Korean Inst Resour Recycl 22:3-11

Noori M, Rashchi F, Babakhani A, Vahidi E (2014) Selective recovery and separation of nickel and vanadium in sulfate media using mixtures of D2EHPA and Cyanex 272. Sep Purif Technol 136:265-273

Park KH, Mohapatra D, Reddy BR (2006) Selective recovery of molybdenum from spent HDS catalyst using oxidative soda ash leach/carbon adsorption method. J Hazard Mater 138:311-316

Rapaport D (2000) Are spent hydrocracking catalysts listed hazardous wastes? Hydrocarb Process 79:49-53

Sahu KK, Agrawal A, Mishra D (2013) Hazardous waste to materials: recovery of molybdenum and vanadium from acidic leach liquor of spent hydroprocessing catalyst using alamine. J Environ Manage 125:68-73

Saily A (1997) Studies on liquid-liquid extraction of molybdenum, tugsten and vanadium using alkylphosphine extractants. Indian Institute of Technology, Roorkee

Saily A, Tandon SN (1998) Liquid-liquid extraction behaviour of V (IV) using phosphinic acids as extractants. Fresenius J Anal Chem 360:266-270

Sato T, Ikoma S, Nakamura T (1980) Solvent extraction of vanadium (IV) from hydrochloric acid solutions by neutral organophosphorus compounds. Hydrometallurgy 6:13-23

Schwarzenbach G, Flaschka H (1969) Complexometric Titrations. Methuen, London

Shaeri M, Torab-Mostaedi M, Rahbar Kelishami A (2015) Solvent extraction of thorium from nitrate medium by TBP, Cyanex272 and their mixture. J Radioanal Nucl Chem 303(3):2093-2099

Srichandan H, Singh S, Kim DJ, Lee S (2013) A comparative study of metal extraction from spent catalyst using acidithiobacillus ferrooxidans. Eng Technol 7:112-116

Tavakoli MR, Dreisinger DB (2014) Separation of vanadium from iron by solvent extraction using acidic and neutral organophosporus extractants. Hydrometallurgy 141:17-23

Wu J, Wei C, Li X, Wang S, Wang M, Li C (2012) Selective extraction of Mo using Cyanex-272 and tributyl phosphate from low grade Ni-Mo ore leach liquor. Sep Purif Technol 99:120-126

Zang $\mathrm{P}$, Inoue $\mathrm{K}$, Tsuyama $\mathrm{H}$ (1996) Solvent extraction of $\mathrm{V}(\mathrm{IV})$ from $\mathrm{H}_{2} \mathrm{SO}_{4}$ acid solution by bis(2,4,4-trimethylpentyl) phosphinic acid by ExxsolD80. J Chem Eng J.pn 29:82

Zeng L, Cheng CY (2009a) A literature review of the recovery of molybdenum and vanadium from spent hydrodesulphurisation catalysts: Part l: Metallurgical processes. Hydrometallurgy 98: 1-9

Zeng L, Yong Cheng C (2009b) A literature review of the recovery of molybdenum and vanadium from spent hydrodesulphurisation catalysts: Part II: Separation and purification. Hydrometallurgy 98: 10-20

Zeng L, Xiao LS, Li QG, Xiang XY (2006) Study of separation of vanadium from ammonium molybdate solution by ion exchange. Rare Metal and Hard Alloy 3:1-4, in Chinese

\section{Submit your manuscript to a SpringerOpen ${ }^{\odot}$ journal and benefit from:}

- Convenient online submission

- Rigorous peer review

- Immediate publication on acceptance

- Open access: articles freely available online

- High visibility within the field

- Retaining the copyright to your article

Submit your next manuscript at springeropen.com 